\title{
A surgical approach of an unusual variant of complete atrioventricular defect; A case report
}

\author{
Hamad Qabha ${ }^{1}$, Tariq Alanazi ${ }^{1}$, Mohamad Khouqeer ${ }^{2}$, Mohannad Dawary ${ }^{3}$ and Fareed Khouqeer ${ }^{3^{*}}$
}

\begin{abstract}
Background: Complete atrioventricular canal is a congenital heart defect that is characterized by an atrial septal defect, ventricular septal defect, and a common atrioventricular valve. Standard surgical techniques for repairing complete atrioventricular canal defect mainly includes repairing the defect with a single patch, a double patch, or with the modified single patch technique.

Case presentation: This paper presents a novel surgical repair technique of an unusual anatomical presentation for a complete atrioventricular canal defect in a patient with Down syndrome.

Conclusions: Unusual anatomical variant for congenital heart defects occurs frequently, which gives surgeons real opportunities to innovate surgical approaches. This patient was an example of an unusual anatomical presentation for complete atrioventricular canal, and the surgical technique used for this patient was novel. Follow up for these patients is mandatory for long term results.
\end{abstract}

Keywords: Congenital heart disease, Atrioventricular canal defect, Atrial septal defect, Ventricular septal defect, Cardiac surgery

\section{Background}

Atrioventricular septal defects (AVSDs) are classified into partial, transitional, intermediate, and complete [1]. Complete atrioventricular canal (CAVC) is a congenital heart defect that is characterized by an ostium primum atrial septal defect (ASD), a common atrioventricular (AV) valve, and inlet ventricular septal defect (VSD) [2]. The pathophysiology behind this defect is thought to be due to the inappropriate development of embryonic endocardial cushion [3]. CAVC accounts for $3.4 \%$ of all congenital heart defects and more than $50 \%$ of congenital heart defects in Down syndrome children [4]. Untreated CAVC contributes to the development of congestive

\footnotetext{
*Correspondence: khouqeer@hotmail.com

3 Department of Cardiac surgery, King Faisal Specialist Hospital \& Research Center, Heart center MBC\#16, P O BOX 3354, Riyadh 11211,

Saudi Arabia

Full list of author information is available at the end of the article
}

heart failure and/or pulmonary hypertension; and $80 \%$ of the cases die in the first 2 years of life if not treated, therefore; repair is highly recommended during infancy and early life $[5,6]$. The optimal age for repair is age 3 to 6 months to lower the risk of early death or development of pulmonary vascular obstructive disease and to decrease any postoperative complications [7]. Surgical techniques mainly includes repairing the defect with a single patch, a double patch, or with the modified single patch (Australian) technique [8]. While the double patch was used more often than other techniques $[8,9]$, comparable results were reported in a recent meta-analysis [10]. In the last decade, mortality after repair of CAVC in the first year of patient life has decreased dramatically [11]. Nevertheless, the reoperation rate is relatively high and accounts for $15 \%$ of the cases [11]. 


\section{Case presentation}

A girl was born with Down syndrome developed respiratory distress in the neonatal period, for which she was admitted to the neonatal intensive care unit. An echocardiogram was done and shows a CAVC (Fig. 1), and (Fig. 2). By the age of five months, her weight reached $4.9 \mathrm{Kg}$, and she was scheduled for surgical intervention.

\section{Surgical technique and postoperative follow-up}

A median sternotomy was performed, and cardiopulmonary bypass was established. An incision was made on the right atrium to expose the AV valve and both

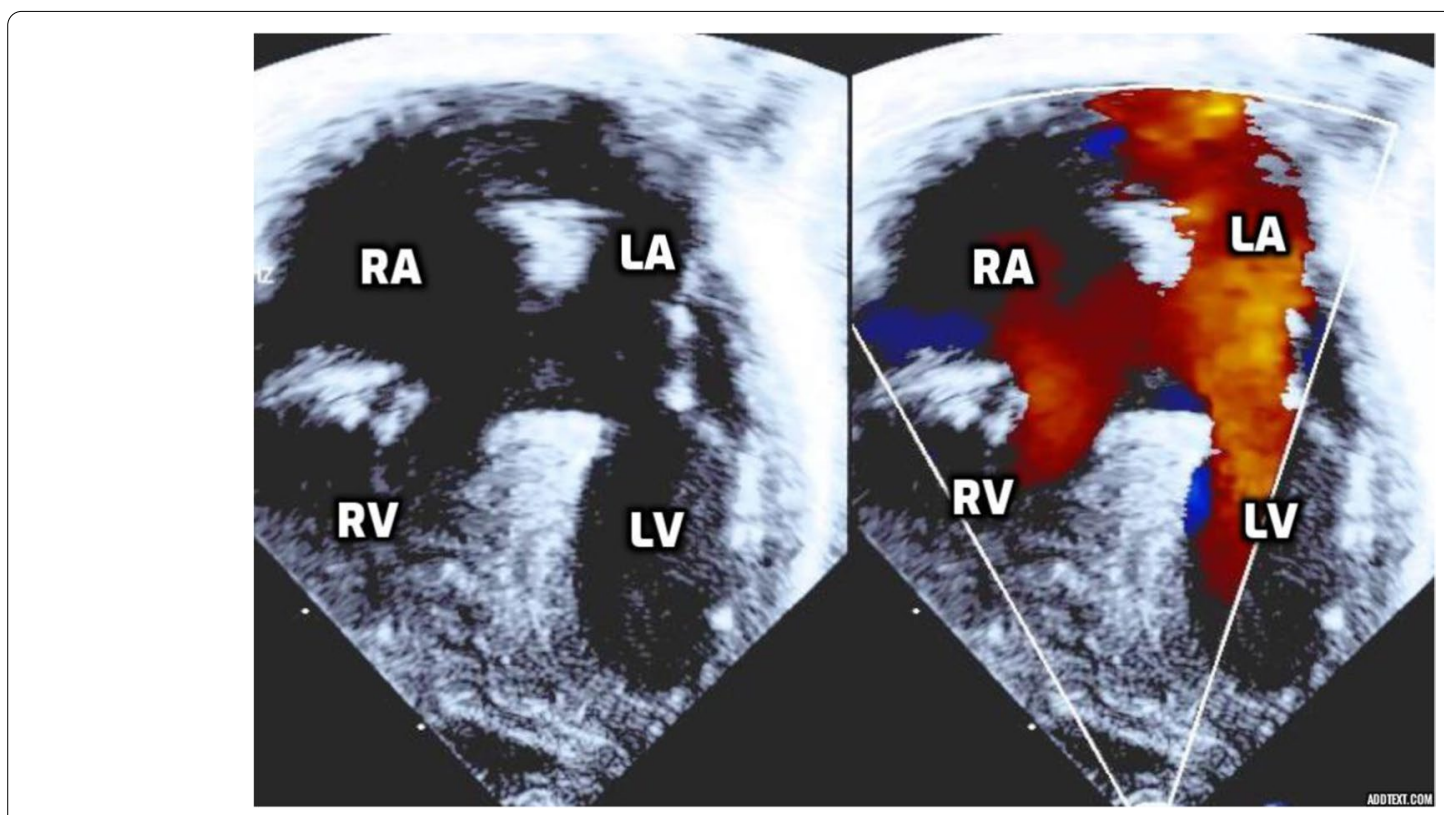

Fig. 1 Preoperative echocardiogram showing complete atrioventricular defect during diastole with large ostium primum shunt. RA= Right Atrium, $\mathrm{RV}=$ Right ventricular, $\mathrm{LA}=$ Left Atrium, $\mathrm{LV}=$ Left Ventricular

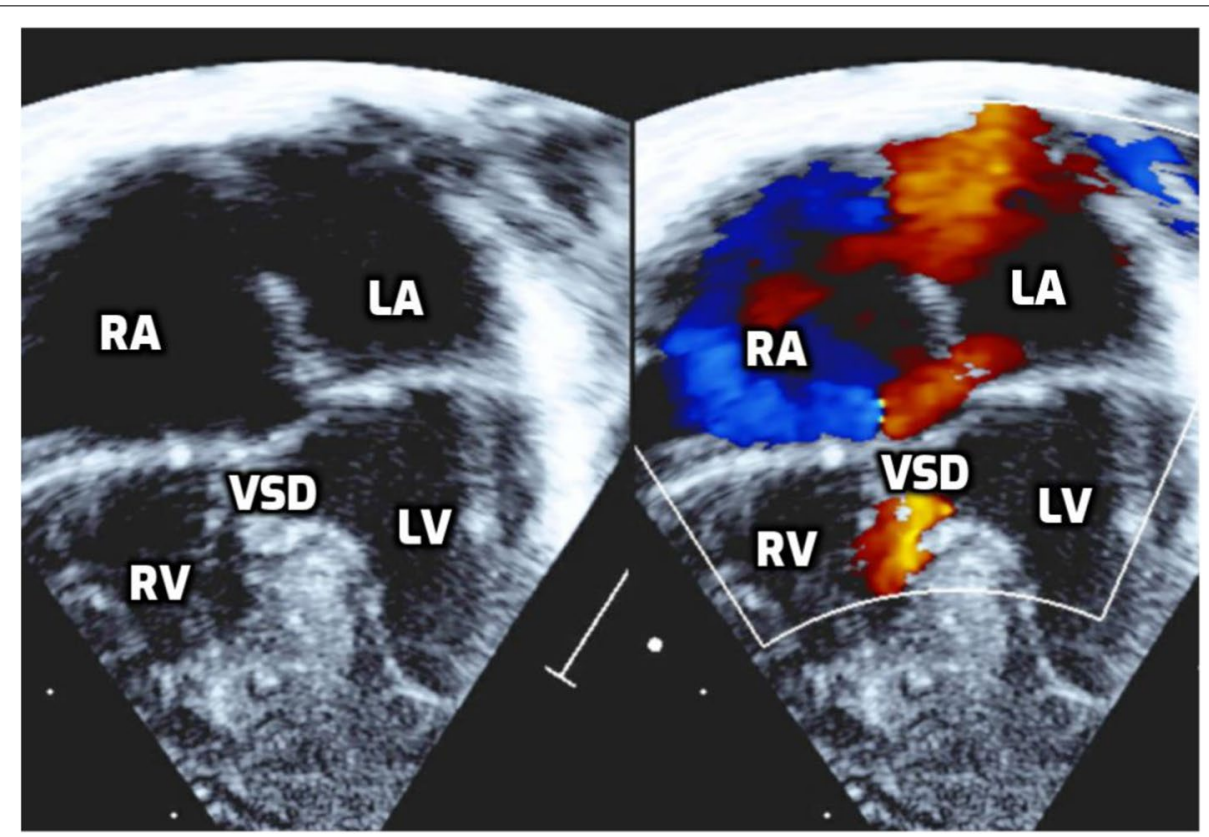

Fig. 2 Preoperative echocardiogram showing complete atrioventricular defect during systole revealing the VSD component shunt 


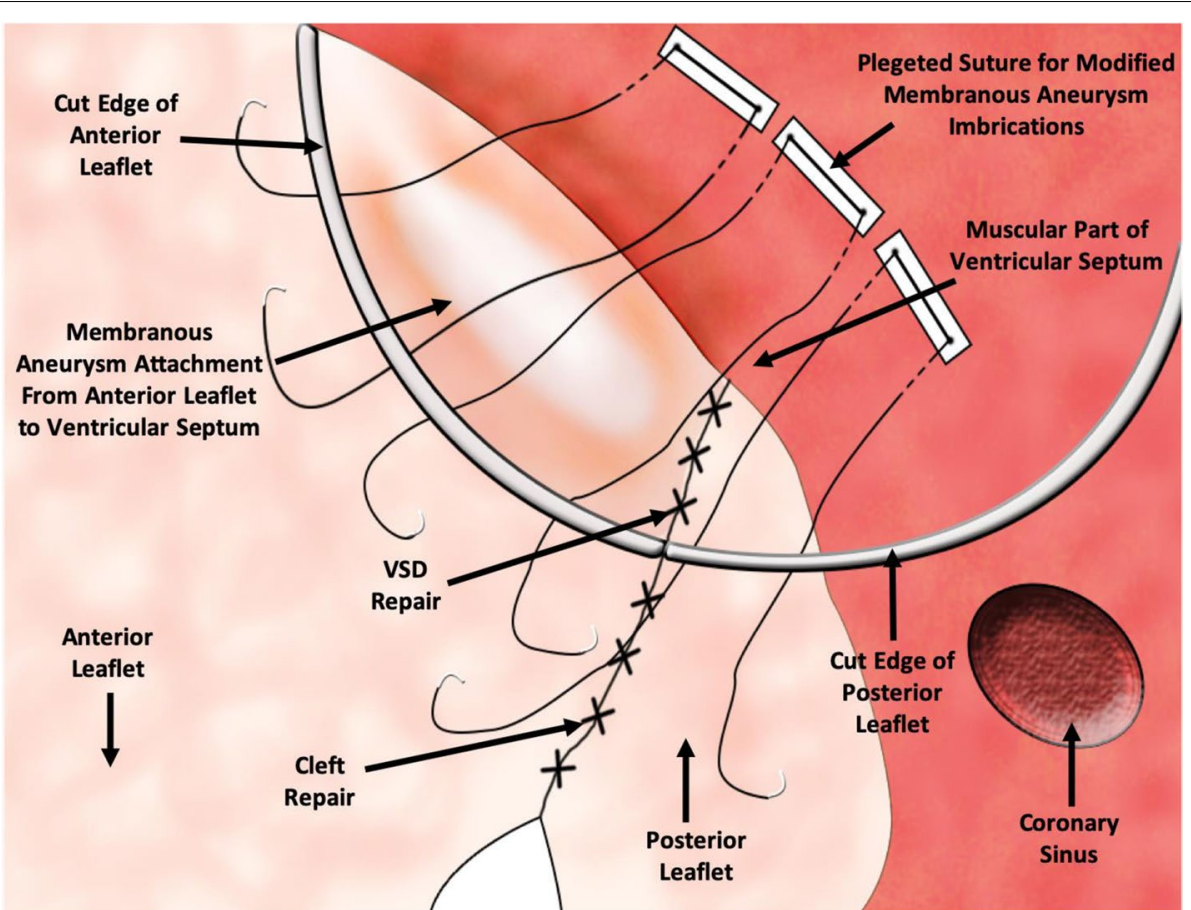

Fig. 3 Showing closing small VSD and cleft repair by sutures and aneurysmal protrusion obliteration by sutures. VSD: Ventricular Septal Defect

ventricles. Passive testing of AV valve using cold normal saline injection into the ventricles revealed mildly incompetent $\mathrm{AV}$ valve. On inspection of the $\mathrm{AV}$ valve, the superior bridging leaflet had attachments to the crest of the ventricular septum anteriorly by membranous tissue which had a crescent-like edge forming the anterior rim of a small VSD component. That membranous tissue also had a weak center that developed into an aneurysm bulging into the right ventricular side. The inferior bridging leaflet was directly adherent to the crest of the ventricular septum. The remaining of the AV valve orifice had two other minor leaflets on each side as depicted in the drawing, and these were only different from the usual reported arrangement in being relatively smaller.

Interrupted 7/0 polypropylene sutures were used to close the small VSD, and similar sutures were used to close

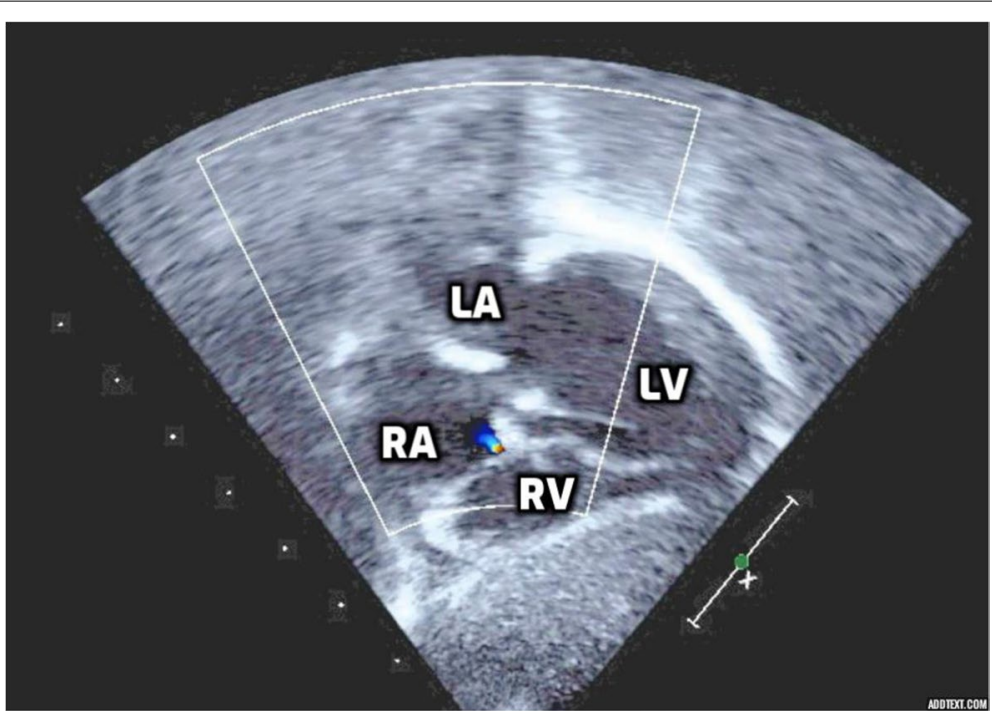

Fig. 4 Postoperative echocardiogram showing no residual septal defect and trivial atrioventricular valve regurgitation. $R A=$ Right $A$ trium, $R V=$ Right Ventricular, $\mathrm{LA}=$ Left Atrium, $\mathrm{LV}=$ Left Ventricular 


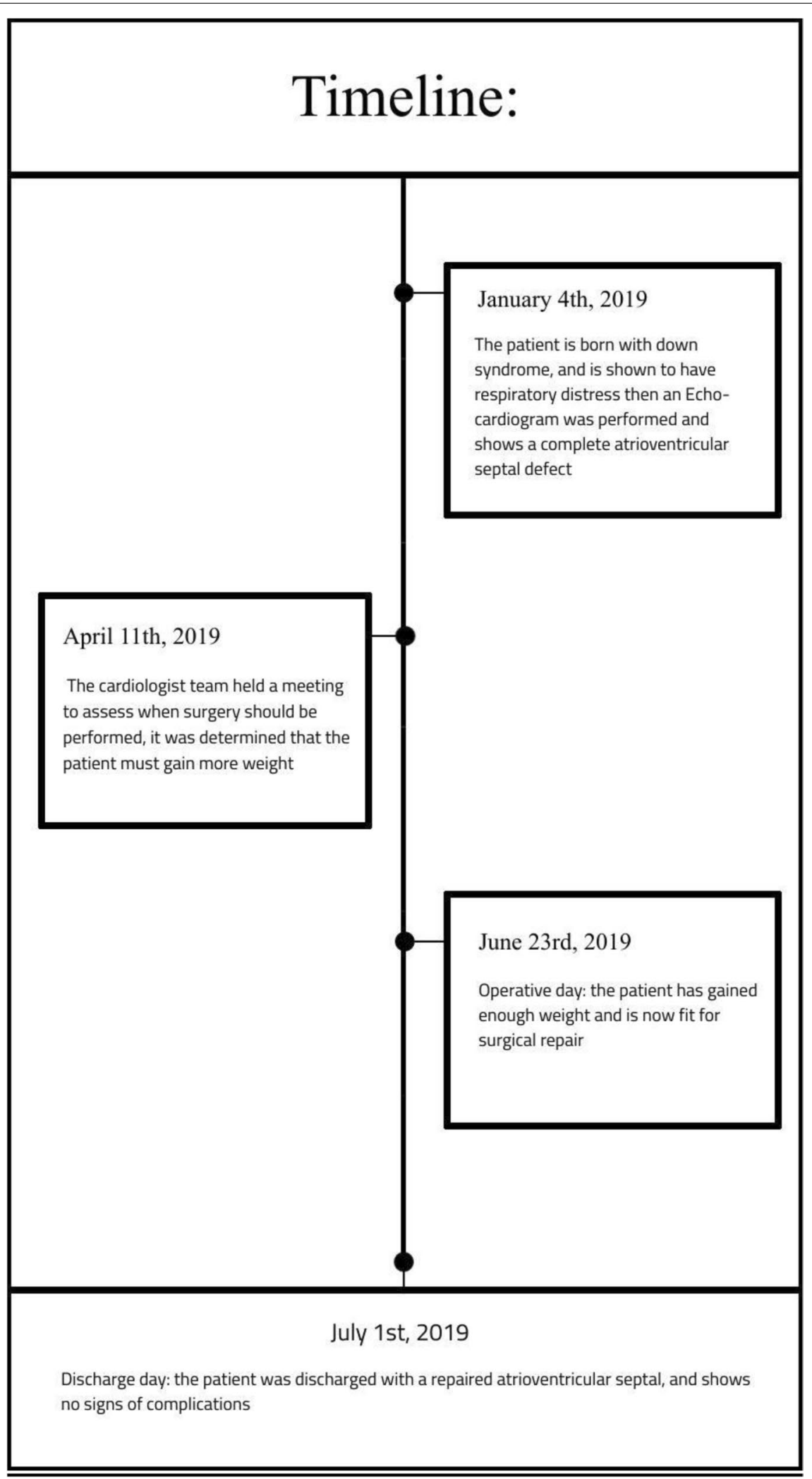

Fig. 5 Timeline of the patient's birth to their discharge after the Complete Atrioventricular Canal repair 
the resulting cleft on the left $\mathrm{AV}$ valve. Again passive testing of the AV valve at that moment revealed a competent valve with an aneurysmal protrusion of the membranes tissue below the anterior bridging leaflet. The anterior part of the superior bridging leaflet was then sutured onto the crest of the ventricular septum using three interrupted plegeted 5/0 Tevdek sutures to obliterate that aneurysm.

The line separating AV valves was suture with interrupted suture to the future autologous pericardial patch. Resulting in separate AV valves into left and right components. The edge of the autologous pericardial patch is used to close the primum defect, committing the coronary sinus to the right atrium (Fig. 3). Before tying the suture, saline injection to the left side reveals no residual leaks across both septa. The right AV valve was competent on saline injection into the right ventricle. The right atrium was closed, and the patient then was rewarmed, and cardiopulmonary bypass was terminated.

Post-operative Echocardiogram reveals no residual septal defects, trivial residual AV valve regurgitation, and no left ventricular outflow tract obstruction (Fig. 4). The patient was then discharged on postoperative day eight after CAVC repair with no sign of complications (Fig. 5).

\section{Conclusions}

Standard surgical techniques for CAVC mainly include the following: single patch, double patch, and the modified single patch repair [8]. Anatomic presentation of CAVC has variable malformations and defects in the heart, and these malformations may affect ASD, VSD, and a common AV valve junction that may contain variable attachment to the septum [5, 12]. Furthermore, CAVC can be classified into subgroups depending on the chordal insertions and the morphology of the superior bridging leaflet of the common AV valve, according to Rastelli's classification, three types have been described, (Types A, B, and C) [13]. As a fact, there are anatomical variations of this congenital anomaly, in this case, the patient was presented at the surgery with the superior bridging leaflet attached by a membranous tissue to the crest of the ventricular septum anteriorly with the small VSD on the inferior aspect. Similarly, the inferior bridging leaflet is entirely adherent to the crest of the ventricular septum. Because of this unusual presentation, the VSD was closed by sutures wherein classical repair techniques of this congenital defect the VSD would be closed by using a patch [14]. Surgical repair continues with the anterior portion of the superior bridging leaflet being sutured to the crest of the ventricular septum to repair aneurysmal protrusion below the anterior leaflet. The unfamiliar anatomical defect of this patient has led to this innovative repair technique that combines parts of different standard techniques.

\section{Abbreviations}

AVSDs: Atrioventricular septal defects; CAVC: Complete atrioventricular canal; ASD: Atrial septal defect; AV: Atrioventricular valve; VSD: Ventricular septal defect.

\section{Acknowledgements \\ Not applicable}

\section{Authors' contributions}

HQ: Data collection and drafting and finalized the paper. TA: Data collection and drafting the paper. MK: Data collection and drafting the paper. MD: Drafting the paper. FK: Critical revision of article and approval of the article. All authors have critically reviewed and approved the final draft and are responsible for the content and similarity index of the manuscript.

\section{Funding}

This research did not receive any specific grant from funding agencies in the public, commercial, or not-for profit sectors.

\section{Availability of data and materials}

The authors confirm that the data supporting the findings of this study are available within the article and its supplementary materials.

\section{Declarations}

\section{Ethics approval and consent to participate}

Ethical approval number: 2215118 from the Research Advisory Council King Faisal Specialist Hospital \& Research Centre. Ethical approval was obtained in June 2019.

\section{Consent for publication}

Written informed consent for publication was obtained.

\section{Competing interests}

The authors declare that they have no competing interests.

\section{Author details}

${ }^{1}$ College of Medicine, Imam Mohammad Ibn Saud Islamic University, Riyadh 11432, Saudi Arabia. ${ }^{2}$ King Saud University, Riyadh 11461, Saudi Arabia. ${ }^{3}$ Department of Cardiac surgery, King Faisal Specialist Hospital \& Research Center, Heart center MBC\#16, P O BOX 3354, Riyadh 11211, Saudi Arabia.

Received: 11 August 2021 Accepted: 13 October 2021

Published online: 02 December 2021

\section{References}

1. Rao PS (2019) Management of Congenital Heart Disease: State of the Art; Part I_ACYANOTIC Heart Defects. Children 6(3):42

2. Singh RR, Warren PS, Reece TB, Ellman P, Peeler BB, Kron IL (2006) Early repair of complete atrioventricular septal defect is safe and effective. Ann Thorac Surg 82(5):1598-1601 discussion 602

3. Al Haddad E, LaPar DJ, Dayton J, Stephens EH, Bacha E (2018) Complete atrioventricular canal repair with a decellularized porcine small intestinal submucosa patch. Congenit Heart Dis 13(6):997-1004

4. IJsselhof R, Gauvreau K, Del Nido P, Nathan M (2017) Technical Performance Score: Predictor of Outcomes in Complete Atrioventricular Septal Defect Repair. Ann Thorac Surg 104(4):1371-1377

5. Macris MP, Ott DA, Cooley DA (1992) Complete atrioventricular canal defect: surgical considerations. Tex Heart Inst J 19(3):239-243

6. Ashfaq A, Brown T, Reemtsen B (2017) Repair of Complete Atrioventricular Septal Defects With Decellularized Extracellular Matrix: Initial and Midterm Outcomes. World J Pediatric Congenital Heart Surg 8(3):310-314

7. St Louis JD, Jodhka U, Jacobs JP, He X, Hill KD, Pasquali SK et al (2014) Contemporary outcomes of complete atrioventricular septal defect repair: 
analysis of the Society of Thoracic Surgeons Congenital Heart Surgery Database. J Thorac Cardiovasc Surg 148(6):2526-2531

8. Atz AM, Hawkins JA, Lu M, Cohen MS, Colan SD, Jaggers J et al (2011) Surgical management of complete atrioventricular septal defect: associations with surgical technique, age, and trisomy 21. J Thorac Cardiovasc Surg 141(6):1371-1379

9. Santos F, Croti UA, Marchi CH, Murakami AN, Brachine JDP, Borim BC et al (2019) Surgical Treatment for Congenital Heart Defects in Down Syndrome Patients. Braz J Cardiovasc Surg 34(1):1-7

10. Li D, Fan Q, Iwase T, Hirata Y, An Q (2017) Modified Single-Patch Technique Versus Two-Patch Technique for the Repair of Complete Atrioventricular Septal Defect: A Meta-Analysis. Pediatr Cardiol 38(7):1456-1464

11. Xie O, Brizard CP, d'Udekem Y, Galati JC, Kelly A, Yong MS et al (2014) Outcomes of repair of complete atrioventricular septal defect in the current era. Eur J Cardio-Thor Surg 45(4):610-617

12. Calabrò R, Limongelli G (2006) Complete atrioventricular canal. Orphanet J Rare Dis 1:8

13. Tchervenkov Cl, Bernier PL, Duca DD, Hill S, Ota N, Samoukovic G et al (2010) Repair of atrioventricular canal with double-outlet right ventricle, transposition, or truncus arteriosus. World J Pediatric Congenital Heart Surg 1(1):119-126

14. Jonas RA (2004) Introduction. Operative Techniques in Thoracic and Cardiovascular Surgery 9(3):193

\section{Publisher's Note}

Springer Nature remains neutral with regard to jurisdictional claims in published maps and institutional affiliations.

\section{Submit your manuscript to a SpringerOpen ${ }^{\circ}$ journal and benefit from:}

- Convenient online submission

- Rigorous peer review

- Open access: articles freely available online

- High visibility within the field

- Retaining the copyright to your article

Submit your next manuscript at $\boldsymbol{\nabla}$ springeropen.com 